\title{
EVALUATION OF LUMBAR VERTEBRA FRACTURES WITH THORACOLUMBAR INJURY CLASSIFICATION AND SEVERITY SCORE
}

\author{
(1) Muhammed Fatih Sarı ${ }^{1}$, (1) Veli Çıtıșlı2 ${ }^{2}$ (1) Ahmet Kayhan³ \\ ${ }^{1}$ Balıkesir University Faculty of Medicine, Department of Neurosurgery, Balıkesir, Turkey \\ ${ }^{2}$ Private Denipol Hospital, Clinic of Neurosurgery, Denizli, Turkey \\ ${ }^{3}$ University of Health Scineces Turkey, Istanbul Haseki Training and Research Hospital, Clinic of Neurosurgery, İstanbul, Turkey
}

\begin{abstract}
Objective: To investigate whether there was a correlation between Thoracolumbar Injury Classification and Severity (TLICS) score and surgical outcome of lumbar fractures.

Materials and Methods: Medical records of 30 patients with traumatic lumbar fracture who were treated surgically in the neurosurgery department of a tertiary care center between April 2004 and July 2011 were retrospectively reviewed. Clinical and radiological data were assessed in conjunction with therapeutic outcomes.

Results: The average age of 30 patients ( 3 females, 10\%; 27 males, 90\%) was $36.4 \pm 10.2$ (range, 20 to 57) years. The most common levels of fracture were L1 ( $n=12,40 \%), L 2$ ( $n=7,23.3 \%)$ and L4 $(n=5,16.7 \%)$. Local kyphosis angle, wedging angle, compression ratio, lumbar lordosis angle and sagittal indices changed significantly after the surgical intervention ( $p<0.001)$. American Spinal Injury Association scores displayed significant improvement after surgery $(\mathrm{p}=0.014)$.

Conclusion: Results of the current study demonstrate that TLICS score seems to reflect the outcome of patients treated surgically for lumbar fracture.
\end{abstract}

Keywords: Spine, fracture, trauma, lumbar, classification, treatment

\section{INTRODUCTION}

High-energy multiple traumas are likely the cause of spinal injuries, particularly on the lumbar vertebra ${ }^{(1)}$. More than $40 \%$ of vertebral fractures occur in the thoracic and lumbar regions and $2 / 3$ of these cases do not display any neurological signs or symptoms. Improvement of neurological outcomes can be accomplished by decompression of neural structures, preservation of proper anatomic configuration, fusion together with rigid stabilization to avoid late neural injury, early mobilization and rehabilitation with the early intervention. Spinal instruments allow a better stabilization until a satisfactory bone fusion is achieved ${ }^{(2)}$.

Some of the thoracolumbar and lumbar burst fractures with intact neurological status can be treated conservatively. However, the presence of spinal instability and neurological disorders should be treated surgically in order to determine the appropriate surgical approach ${ }^{(3)}$. In spite of technological and medical development, there are still many obscure points for the selection of optimal treatment modality. Treatment decisions in spinal injury patients must be made on the basis of a full assessment of neurological status and identification of the spinal instability ${ }^{(1-3)}$. Even though there is no consensus on the standard international classification system for determining the optimal management modality for patients with thoracolumbar fracture, Thoracolumbar Injury Classification and Severity Score (TLICS) is a valid and reliable method used in the management of thoracolumbar injuries ${ }^{(4)}$.

The aim of the current study was to investigate the efficacy of TLICS to predict the therapeutic outcomes of the surgical management of lumbar fractures.

\section{MATERIALS AND METHODS}

\section{Study Design}

This retrospective study was approved by the local Institutional Review Board (2012/70). Written informed consent for the

Address for Correspondence: Muhammed Fatih Sarı, Balıkesir University Faculty of Medicine, Department of Neurosurgery, Balıkesir, Turkey Phone: +90 5558786808 E-mail: mefese@hotmail.com Received: 28.05.2021 Accepted: 02.11.2021

ORCID ID: orcid.org/0000-0001-7200-8915 
usage of data in medical files has been routinely obtained from all subjects, a legal surrogate, the parents or legal guardians. The medical records from files of 30 patients suffering from traumatic lumbar vertebral fracture that had been surgically treated in the neurosurgery department of our tertiary center, between April 2004 and July 2011 were retrospectively reviewed. Fractures of non-traumatic aetiology (osteoporosis, malignancy etc.) were excluded. Routine blood tests, plain radiographs viewing cranial, cervical and lumbar regions, computerized tomography scans and magnetic resonance images were obtained before and after the surgery. This study has been approved by the Balıkesir University Faculty of Medicine, Clinical Research Ethics Committee (date: 22.06.2021, number: 13743348/020/42491) and have been performed in accordance with the ethical standards laid down in the 1964 Declaration of Helsinki and its later amendments (2021/136).

The sliding, angulation, compression and distance between pedicles were measured at the site of lumbar fractures on the anteroposterior and lateral views of radiographs. Angles of lumbar lordosis, wedging and local kyphosis were calculated and compression ratios were assessed. The sagittal index was calculated bysubtracting physiological kyphosis angle from local kyphosis angle. Assessment of fractures was made radiologically with respect to Arbeitsgemeinschaft für Osteosynthesefragen (AO) classification ${ }^{(5-7)}$. The initial neurological examination included evaluation of sensory and motor functions, Achilles, patellar tendon and Babinski reflexes, as well as anal tonus, perianal sensation, bulbocavernosus reflex and abdominal skin reflexes. Findings obtained from the neurological evaluation were classified with respect to the American Spinal Injury Association (ASIA) impairment scale ${ }^{(8)}$.

Thoracostomy tubes were applied to patients operated via the anterior approach. Postoperative antibiotic prophylaxis was initiated and respiratory exercises were instructed routinely. Sutures were removed on the $12^{\text {th }}$ postoperative day. Patients were controlled on the $4^{\text {th }}$ week, $6^{\text {th }}$ and $12^{\text {th }}$ months.

\section{Outcome Parameters}

Descriptive parameters were recorded and sites of fracture, angles of lumbar lordosis, wedging and local kyphosis; compression ratios and sagittal indices were determined for every patient. Patients were classified according to AO classification, ASIA impairment scale and TLICS. Clinical and radiological alterations after surgery were noted and compared with respect to these aforementioned classifications.

Radiological parameters were defined as follows:

1. Lumbar lordosis angle: The angle formed by the intersection of the lines drawn parallel to the upper margin of the first lumbar and first sacral vertebra (Figure 1).

2. Wedging angle: The angle between lines passing in parallel through the upper and lower plates of the injured vertebra, Angle A (Figure 2).

3. Local kyphosis angle: It is formed by the intersection of lines passing in parallel through the intact upper plate of the uninjured vertebra above and the lower intact plate of the uninjured vertebra below, Angle B (Figure 2).

4. Compression ratio: The anterior height of the corpus of the injured vertebra is termed as $A$ and the anterior height of the corpus of the uninjured vertebra below is termed as $B$. Compression ratio is calculated according to the formula, (1B/A)X100.

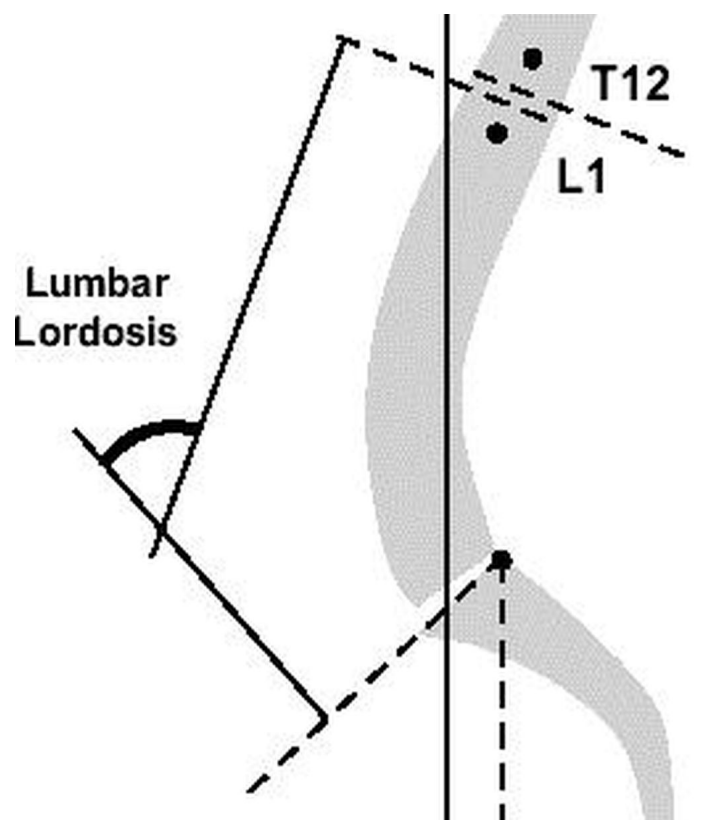

Figure 1. Lumbar lordosis angle is formed by the intersection of the lines drawn parallel to the upper margin of first lumbar and first sacral vertebra

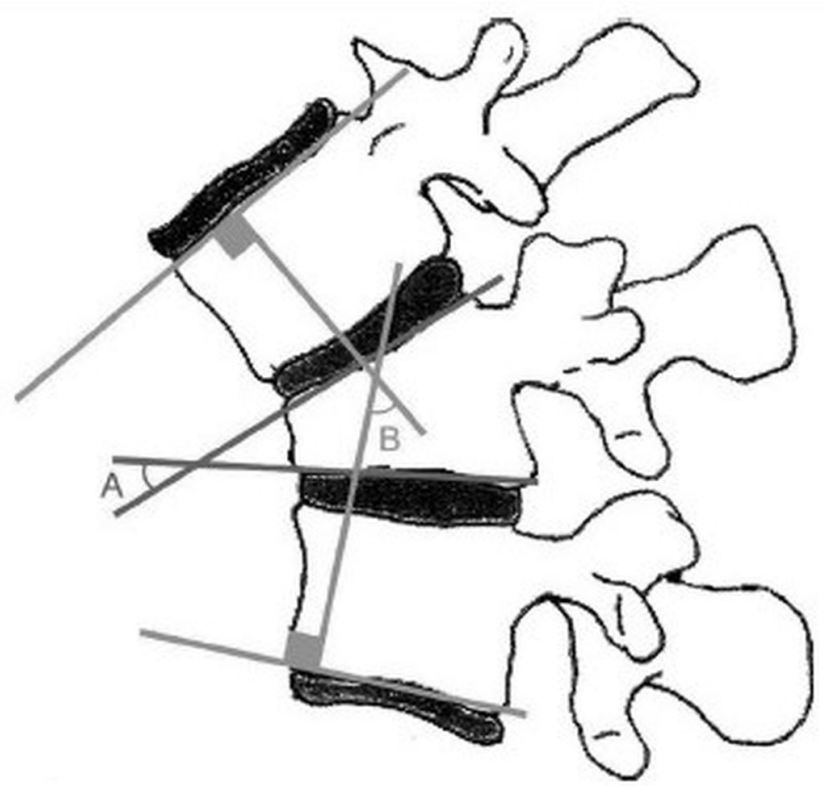

Figure 2. A) Wedging angle exists between lines passing in parallel through the upper and lower plates of the injured vertebra; B) Local kyphosis angle formed by the intersection of lines passing in parallel through the upper intact plate of the uninjured vertebra above and the lower intact plate of the uninjured vertebra below 
turkishspine

5. Sagittal index: It is calculated by subtraction of the physiological kyphosis angle from the local kyphosis angle measured. The normal physiological kyphosis angles are $5^{\circ}$ for vertebra between T1-T12, $0^{\circ}$ for vertebra between T12-L1 and $-10^{\circ}$ for the level between $L 2$ and $L 5^{(9)}$. The normal value of the sagittal index varies between 15-20, increase beyond these boundaries constitute a surgical indication ${ }^{(10)}$.

\section{Statistical Analysis}

Data were analysed using the Statistical Package for Social Sciences software (version 15.0 for Windows). All differences associated with a chance probability of 0.05 or less were considered statistically significant. Continuous variables are presented as mean \pm standard deviation. Since variables did not display normal distribution, non-parametric methods were used. Independent groups were compared using the Mann-Whitney test, while matched groups were compared via Wilcoxon signed-rank test. Type 1 error ratio $(\alpha)$ was selected as 0.05 and two-way analysis was performed. The level of statistical significance was set at $p<0.05$.

\section{RESULTS}

Thirty patients with lumbar vertebral fractures met the eligibility criteria for the study. Twenty-seven out of 30 patients were male with an average age of $36.4 \pm 10.2$ (range, 20 to 57) years. The average duration of hospitalization was 12.1 days (range: 4-22). The level of fracture was L1 (12 cases, 40\%), L2 (7 cases, $23.3 \%$ ), L4 (5 cases, $16.7 \%$ ), L3 (4 cases, $13.3 \%$ ) and L5 (2 cases, 6.7\%). Categorization of patients according to AO classification yielded that 21 cases (70\%) had type B and 9 patients (30\%) type $\mathrm{C}$ fractures. The types of injury leading to lumbar fracture were falling from height (60\%), traffic accidents (26.7\%) and other causes (13.3\%).

Revision surgery was required in one patient (3.3\%) with L3 fracture and replacement of pedicle screw was accomplished eventually. No serious complications such as wound infection, cerebrospinal fluid leakage and pulmonary thromboembolism were identified.
Comparison of preoperative and postoperative ASIA scores indicated a significant improvement after surgical intervention $(p=0.014)$ (Table 1).

When the patients were grouped into two according to TLICS scores, it was observed that patients with TLICS scores $<5$ had higher preoperative $(p=0.002)$ and postoperative ASIA scores $(p=0.001)$ (Table 1). There were statistically significant changes in all radiological indices after the surgical intervention ( $p<0.001$ for all variables) (Table 2$)$.

Table 1. Comparison of descriptive and radiological parameters in patients with TLICS $<5$ and TLICS $\geqslant 5$

\begin{tabular}{|c|c|c|c|c|c|}
\hline \multirow{2}{*}{$\begin{array}{l}\text { Parameter } \\
<5\end{array}$} & & \multicolumn{2}{|c|}{ TLICS } & \multirow{2}{*}{ Total } & \multirow{2}{*}{$\%$} \\
\hline & & $\geqslant 5$ & & & \\
\hline \multirow{4}{*}{ Age (years) } & $20-29$ & 4 & 6 & 10 & 33.3 \\
\hline & $30-39$ & 3 & 5 & 8 & 26.7 \\
\hline & $40-49$ & 5 & 3 & 8 & 26.7 \\
\hline & $50-59$ & 2 & 2 & 4 & 13.3 \\
\hline \multirow{5}{*}{ Level } & L1 & 4 & 8 & 12 & 40 \\
\hline & L2 & 4 & 3 & 7 & 23.3 \\
\hline & L3 & 3 & 1 & 4 & 13.3 \\
\hline & L4 & 1 & 4 & 5 & 16.7 \\
\hline & L5 & 2 & 0 & 2 & 6.7 \\
\hline \multirow{2}{*}{ AO fracture type } & B & 14 & 7 & 21 & 70 \\
\hline & C & 0 & 9 & 9 & 30 \\
\hline \multirow{4}{*}{$\begin{array}{l}\text { Preoperative ASIA } \\
\text { impairment scale }\end{array}$} & A & 0 & 2 & 2 & 6.7 \\
\hline & $\mathrm{C}$ & 0 & 4 & 4 & 13.3 \\
\hline & D & 2 & 5 & 7 & 23.3 \\
\hline & $\mathbf{E}$ & 12 & 5 & 17 & 56.7 \\
\hline \multirow{4}{*}{$\begin{array}{l}\text { Postoperative ASIA } \\
\text { impairment scale }\end{array}$} & $\mathbf{A}$ & 0 & 2 & 2 & 6.7 \\
\hline & $\mathrm{C}$ & 0 & 2 & 2 & 6.7 \\
\hline & D & 0 & 5 & 5 & 16.6 \\
\hline & $\mathbf{E}$ & 14 & 7 & 21 & 70 \\
\hline
\end{tabular}

TLICS: Thoracolumbar injury classification and severity score, AO: Arbeitsgemeinschaft für Osteosynthesefragen Spine System, ASIA: American Spinal Injury Association

Table 2. Comparison of alterations in radiological parameters before and after the surgery

\begin{tabular}{llll}
\hline \multirow{2}{*}{ Compression ratio } & & Median & Range (min - max) \\
\hline \multirow{2}{*}{ Wedging angle } & Preoperative & 48.5 & $10-72$ \\
\cline { 2 - 4 } & Postoperative & 24.5 & $0-52$ \\
\hline \multirow{2}{*}{ Local kyphosis angle } & Preoperative & 18.0 & $0-38$ \\
\cline { 2 - 4 } & Postoperative & 10.0 & $0-18$ \\
\hline \multirow{2}{*}{ Lumbar lordosis angle } & Preoperative & 15.5 & $4-33$ \\
\cline { 2 - 4 } & Postoperative & 10.0 & $1-29$ \\
\hline \multirow{2}{*}{ Sagittal index } & Preoperative & 43.0 & $19-68$ \\
\cline { 2 - 4 } & Postoperative & 37.5 & $21-69$ \\
\hline \multirow{2}{*}{$:$ Statistically } & 22.0 & $11-43$ \\
\hline \multirow{2}{*}{ Preoperative } & 17.5 & $1-39$ \\
\hline
\end{tabular}

*: Statistically significant, min: Minimum, max: Maximum 
The clinical and radiological findings of a case from our cohort are shared in Figures 3 and 4.

\section{DISCUSSION}

In this study, we determined that TLICS is a good indicator to predict the therapeutic outcomes for patients who were treated surgically due to traumatic lumbar fractures.

More than half of the cases presenting with vertebral fractures involving the thoracolumbar region do not result in any neurological findings, and therefore would not be good candidates for surgical interventions ${ }^{(3)}$. The decision

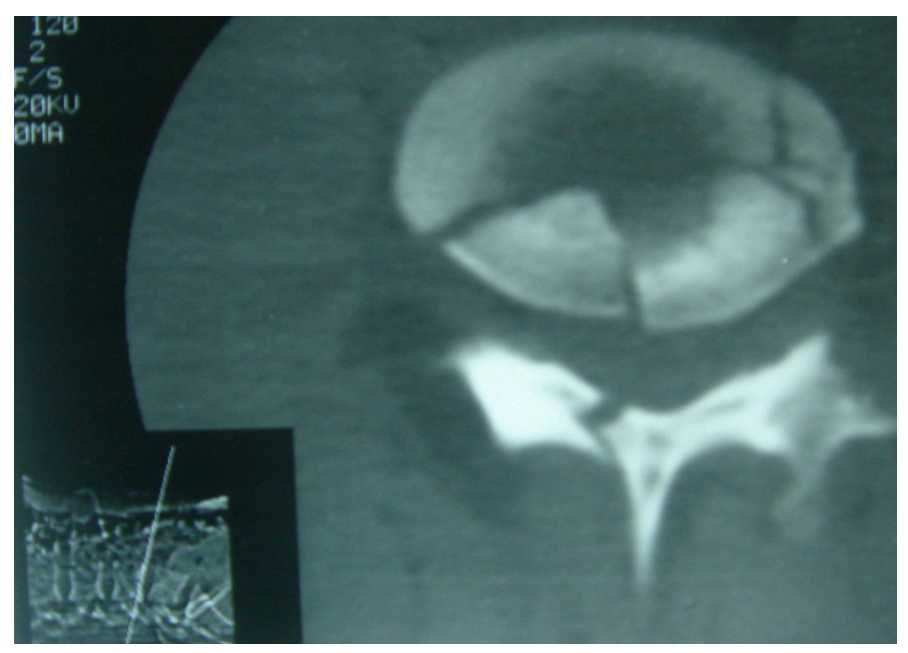

Figure 3. A case from our cohort: A 25-year-old male patient was brought to the emergency room with both legs paralyzed after a traffic accident. In addition to instrumentation and fusion procedures, this patient underwent L4 total laminectomy and primary dural repair. Postoperative ASIA score increased from C to D. Lumbar CT axial image demonstrate L4 burst fracture

CT: Computed tomography, ASIA: American Spinal Injury Association

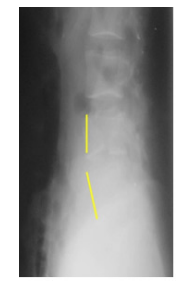

Preop : 30

4a. Compression ratio

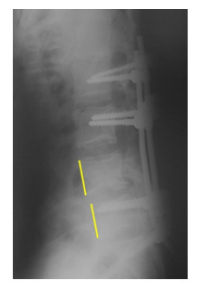

Postop: 0

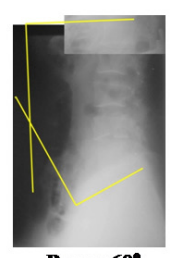

Preop:60

4c. Lumbar lordosis angle

Figure 4. The patient's radiological measurements are demonstrate in the lumbar X-ray images

Preop: Preoperative, Postop: Postoperative for therapeutic approach necessitates a prompt neurological examination and definition of the presence of spinal instability $^{(11)}$. Despite the development of many classification systems to guide the determination of optimal therapeutic approach, there is no consensus yet ${ }^{(2,3)}$. The management of a patient with a vertebral injury must be started at the site of the event and any patient claiming pain on vertebral column or any unconscious patient must be presumably considered as a vertebral fracture until the diagnosis is ruled out ${ }^{(12)}$. Since vertebral fractures may be accompanied by injuries of other parts of the body including the head, thorax, abdomen and pelvis as well, the patients exposed to multiple traumas must be handled on a multi-disciplinary basis and an algorithm must be planned with respect to the priority of vital organs ${ }^{(2)}$.

AO classification is commonly used in clinical practice for vertebral fractures; however, it possesses some limitations in terms of prognostic and morphologic aspects ${ }^{(5-7)}$. Vaccaro et al. ${ }^{(4)}$ has proposed a novel scoring system, TLICS, that permits a better evaluation in terms of anatomical structure and neurologic state $^{(13,14)}$. Type of injury (compression, rotation or distraction), neuronal root involvement and extent of conus medullaris injury are taken into account in TLICS. Posterior ligamentous complex (PLC) injury requires the addition of 3 points to the score. Conservative approach is advocated for cases with TLICS $\leqslant 3$, either surgery or conservative approach can be preferred for patients with TLICS of 4 and surgical intervention is advocated for TLICS $\geqslant 5^{(4,15,16)}$. Recent publications have documented the validity and reliability of TLICS(14-17).

There is a debate on the treatment protocol of burst fractures that do not cause any neurological deficits and PLC injury. Since the conservative approach is associated with an increased likelihood of further problems like post-traumatic kyphosis and neurological defects, surgery was found to be superior ${ }^{(1,2)}$. Criteria that favour surgical treatment include stenosis of vertebral canal $>50 \%$, local kyphosis angle $>20^{\circ}$, collapse $>50 \%$ on the anterior column, progressive incomplete paraplegia and tear on PLC(18).

Analysis of our results demonstrated that most patients presenting with lumbar fracture were at $4^{\text {th }}$ decade and the most common ethology was fall from height. The most common site of injury was L1 (40\%) and the most frequent type of fracture was burst (70\%). In 2 cases (6.7\%), there was complete neurological deficit (ASIAA), while 11 patients (36.6\%) presented with incomplete neurological injury (ASIA B-D). Six of the 11 patients presenting with incomplete neurological injury had recovery in the early postoperative period. Nevertheless, there was no improvement in two patients with presenting with complete neurological deficit. All patients were treated surgically and no mortality was detected in our series. In seven cases $(23.3 \%)$, there were additional injuries else than lumbar fracture. TLICS scores seem to reflect the prognostic outcome for patients with lumbar fractures. Therefore, we suggest that TLICS constitutes a valid and reliable guide for 
the preoperative assessment, management plan and disability decision of patients with traumatic lumbar fracture.

\section{Study Limitations}

Limitations of our study are the retrospective design and the relatively small size of our series. Moreover, personal, metabolic, genetic and environmental factors prone to affect the outcomes may be ignored during gathering data from the files. Due to these restrictions, associations should be interpreted with caution. However, we hope that this study will pioneer further studies on this method.

\section{CONCLUSION}

To conclude, the results of the current study demonstrated that TLICS is a good scoring method to reflect the therapeutic success and prognostic outcomes of patients who undergoing surgical intervention for traumatic lumbar fracture.

\section{Ethics}

Ethics Committee Approval: This study has been approved by the Balıkesir University Faculty of Medicine, Clinical Research Ethics Committee (date: 22.06.2021, number: 13743348/020/42491).

Informed Consent: Written informed consent for the usage of data in medical files has been routinely obtained from all subjects, a legal surrogate, the parents or legal guardians.

\section{Authorship Contributions}

Surgical and Medical Practices: M.F.S., V.Ç., A.K., Concept: M.F.S., V.Ç., A.K., Design: M.F.S., V.Ç., A.K., Data Collection or Processing: M.F.S., V.Ç., A.K., Data analysis or Interpretation: M.F.S., V.Ç., A.K., Literature Search: M.F.S., V.Ç., A.K., Writing: M.F.S., V.Ç., A.K.

Peer-review: Internally peer-reviewed.

Financial Disclosure: The authors declared that this study received no financial support.

Conflict of Interest: The authors have no conflicts of interest to declare.

\section{REFERENCES}

1. Wood KB, Li W, Lebl DS, Ploumis A. Management of thoracolumbar spine fractures. Spine J. 2014;14:145-64.

2. Abudou $M$, Chen $X$, Kong $X$, Wu T. Surgical versus non-surgical treatment for thoracolumbar burst fractures without neurological deficit. Cochrane Database Syst Rev. 2013;6:CD005079.
3. Ghobrial GM, Jallo J. Thoracolumbar spine trauma: review of the evidence. J Neurosurg Sci. 2013;57:115-22.

4. Vaccaro AR, Lehman RA Jr, Hurlbert RJ, Anderson PA, Harris M, Hedlund $R$, et al. A new classification of thoracolumbar injuries: the importance of injury morphology, the integrity of the posterior ligamentous complex, and neurologic status. Spine (Phila Pa 1976) 2005;30:2325-33.

5. Aebi M. AO spine classification system for thoracolumbar fractures. Eur Spine J. 2013;22:2147-8.

6. Joaquim AF, Patel AA. Relationships between the Arbeitsgemeinschaft für Osteosynthesefragen Spine System and the Thoracolumbar Injury Classification System: an analysis of the literature. J Spinal Cord Med. 2013;36:586-90.

7. Reinhold M, Audigé L, Schnake KJ, Bellabarba C, Dai LY, Oner FC. AO spine injury classification system: a revision proposal for the thoracic and lumbar spine. Eur Spine J. 2013;22:2184-201.

8. American Spinal Injury Association (ASIA). Standards for neurological and functional classişcation of spinal cord injury (revised). Chicago: ASIA, Chicago 2012.

9. Farcy JP, Weidenbaum M, Glassman SD. Sagittal index in management of thoracolumbar burst fractures. Spine (Phila Pa 1976). 1990;15:958-65.

10. Schoenfeld AJ, Wood KB, Fisher CF, Fehlings M, Oner FC, Bouchard K, et al. Posttraumatic kyphosis: current state of diagnosis and treatment: results of a multinational survey of spine trauma surgeons. J Spinal Disord Tech. 2010;23:e1-8. doi: 10.1097/BSD.0b013e3181c03517.

11. Denis $F$. The three column spine and its significance in the classification of acute thoracolumbar spinal injuries. Spine (Phila Pa 1976). 1983;8:817-31.

12. Aydin E, Solak AS, Tuzuner MM, Benli IT, Kis M. Z-plate instrumentation in thoracolumbar spinal fractures. Bull Hosp Jt Dis 1999;58:92-7.

13. Lee JY, Vaccaro AR, Lim MR, Oner FC, Hulbert RJ, Hedlund R, et al. Thoracolumbar injury classification and severity score: a new paradigm for the treatment of thoracolumbar spine trauma. J Orthop Sci. 2005;10:671-5.

14. Bono CM, Vaccaro AR, Hurlbert RJ, Arnold P, Oner FC, Harrop J, et al. Validating a newly proposed classification system for thoracolumbar spine trauma: looking to the future of the thoracolumbar injury classification and severity score. J Orthop Trauma. 2006;20:567-72.

15. Rihn JA, Anderson DT, Harris E, Lawrence J, Jonsson H, Wilsey J, et al. A review of the TLICS system: a novel, user-friendly thoracolumbar trauma classification system. Acta Orthop. 2008;79:461-6.

16. Koh YD, Kim DJ, Koh YW. Reliability and Validity of Thoracolumbar Injury Classification and Severity Score (TLICS). Asian Spine J. 2010;4:109-17.

17. Patel AA, Whang PG, Brodke DS, Agarwal A, Hong J, Fernandez $C$ et al. Evaluation of two novel thoracolumbar trauma classification systems. Indian J Orthop. 2007;41:322-326.

18. DeWald RL. Burst fractures of the thoracic and lumbar spine. Clin Orthop Relat Res. 1984;189:150-61. 